УДК 551.58:504.064.2(470.65)

КОМПЛЕКСНАЯ ХАРАКТЕРИСТИКА СЕЛЕВЫХ ЯВЛЕНИЙ РЕСПУБЛИКИ СЕВЕРНАЯ ОСЕТИЯ - АЛАНИЯ (ЦЕНТРАЛЬНЫЙ КАВКАЗ)

\author{
Сергеева Г.А., Андреева Е.С., Адамян В.Л.
}

ФБГОУ ВО «Донской государственный технический университет», Ростов-на-Дону, e-mail:sergeeva_ga@mail.ru

\begin{abstract}
В статье рассмотрены морфологические типы селевых очагов, генетические типы селевых потоков, причины формирования дождевых, ледниковых, снеговых селей на территории Республики Северная Осетия - Алания. Даны комплексная характеристика селевых явлений и их количественная оценка по основным речным бассейнам Республики. Основной особенностью селевых потоков в горной части является то, что они формируются не на главных реках, а на их притоках и даже на притоках притоков, во время движения по которым они размывают днища русел, значительно увеличивая свою твердую составляющую. Как показали проведенные исследования, объемы единовременных выносов грязекаменных потоков и максимальные расходы наносоводных потоков наряду с некоторыми другими характеристиками определяют степень опасности селевых бассейнов. Описываемые в статье явления схода селевых потоков наносят значительный ущерб хозяйствам отдельных районов Республики, иногда их прохождение сопровождается человеческими жертвами. В дальнейшем, по мере возрастания рекреационного и хозяйственного освоения горных районов Республики Северная Осетия - Алания, особенно при развитии горнорудной промышленности, строительстве автомобильных дорог, интенсивных лесоразработках и выпасе скота, будет возрастать и активность селеопасных районов, а следовательно, и селевая опасность. Данная статья опирается на результаты проведенных ранее исследований, включает в себя обзор научно-технических отчетов, а также научных публикаций отдела высокогорных гидрометеорологических исследований Северо-Кавказского УГМС, содержит данные о селепроявлениях, изложенные в ряде литературных источников, архивных и справочных материалах, и представляет собой опыт обобщения и систематизации имеющихся материалов о селевой деятельности на территории Северо-Кавказского региона.
\end{abstract}

Ключевые слова: селевые явления, селеформирование, наносоводные селевые потоки, грязекаменные сели, антропогенное вмешательство

\title{
COMPREHENSIVE CHARACTERIZATION OF THE MUD PHENOMENA OF THE REPUBLIC OF NORTH OSSETIA - ALANIA (CENTRAL CAUCASUS)
}

Sergeeva G.A., Andreeva E.S., Adamyan V.L.

Donskoy State Technical University, Rostov-on-Don, e-mail: sergeeva_ga@mail.ru

The article deals with the morphological types of mudslides, genetic types of mudflows, the causes of the formation of rain, glacial, snow mudslides on the territory of the Republic of North Ossetia-Alania. A comprehensive description of mudflow phenomena and their quantitative assessment for the main river basins of the Republic is given. The main feature of mudflows in the mountainous part is that they are formed not on the main rivers, but on their tributaries and even on the tributaries of tributaries, during the movement of which they erode the bottoms of the channels, significantly increasing their solid component. As shown by the research, the volume of simultaneous outflows of mudstone flows and the maximum expenditure of sediment flows, along with some other characteristics, determine the degree of danger of mudflow basins. The phenomena of mudslides described in the article cause significant damage to the economy of certain regions of the Republic, sometimes their passage is accompanied by human casualties. In the future, as the recreational and economic development of the mountainous regions of the Republic of North Ossetia-Alania increases, especially by the mining industry, road construction, intensive logging and livestock grazing, the activity of mudslide-prone areas will also increase, and, consequently, the mudflow hazard. This article is based on the results of previous research, includes a review of scientific and technical reports, as well as scientific publications of the Department of high-altitude hydrometeorological research of the North Caucasus UGMS, contains data on mudslides described in a number of literary sources, archival and reference materials, and represents an experience of generalization and systematization of available materials on mudslide activity in the North Caucasus region

Keywords: village phenomena, seleforming, nano-water mudflows, mud-stone villages, anthropogenic intervention

Хозяйственное освоение горных и предгорных территорий Северо-Кавказского региона определяет необходимость глубокого и всестороннего изучения стихийных бедствий, к числу которых относятся селевые потоки.

Селевая активность территории связана с наличием рыхлообломочного материала гравитационного и эрозионного происхож- дения, расположенного в верховьях многочисленных притоков основных рек, и с обилием выпадающих атмосферных осадков. Водная составляющая селей поступает за счет интенсивных ливней, обложных дождей, таяния сезонного снежного покрова, снежников и ледников, прорыва плотин горных озер и запруд обвально-оползневых масс. 
В связи со смягчением зимних температур, которое, по имеющимся долгосрочным прогнозам, будет продолжаться, селевая деятельность усиливается и еще больше возрастет в середине XXI столетия. Для снижения риска существенных социально-экономических последствий, как представляется, необходимо резко увеличить объемы противоселевых мероприятий [1], направленных на строительство селезащитных дамб, селепропускных лотков, отселение части населения в безопасные районы, а также на проведение экспертизы на селеопасность в отношении строящегося жилья и хозяйственных объектов в горных районах.

С учетом всего вышесказанного настоящее исследование нацелено на изучение особенностей формирования селевых потоков Республики Северная Осетия - Алания. Для достижения этой цели были решены такие задачи, как: анализ имеющихся материалов об особенностях селевой деятельности в горных районах Кавказа; обобщение и оценка факторов регионального селеформирования; многокомпонентная характеристика специфики селепроявлений.

\section{Материалы и методы исследования}

Данная статья основана на проведенных ранее научных изысканиях, научно-технических отчетах, документах и публикациях отдела высокогорных гидрометеорологических исследований Северо-Кавказского УГМС, а также на данных о селепроявлениях, содержащихся в литературных источниках, архивных и справочных материалах о селевой деятельности в долинах главных рек Республики Северная Осетия - Алания за 1834-2014 гг.

\section{Результаты исследования и их обсуждение}

В Республике Северная Осетия - Алания селевые явления образуются практически на всех склонах горных хребтов, к числу которых можно отнести: северные и южные слоны Бокового и Главного хребтов; северные склоны Южного Бокового хребта с такими его отрогами, как: Скалистый, Пастбищный, Лесистый. Кроме прочего, формирование селевых потоков отмечено в пределах Терского, КабардиноСунженского хребтов и депрессиях между ними, а также в Аргуданской предгорной холмистой возвышенности.

В пределах изучаемой горной Республики Северная Осетия - Алания, как показали проведенные ранее геоморфологические исследования [1], нашли распространение такие морфологически обусловленные типы селеопасных областей, расположенных в непосредственной близости друг к другу, как: врезы, рытвины, скальные очаги, а также эродированные поверхности. В свою очередь области рассредоточенного проявления селевых очагов отмечены намного реже, однако возможно их взаимодействие с селевыми областями других морфологических типов. Как известно, селевые врезы, сосредоточенные в высокогорьях и присутствующие в моренных и флювиогляциальных толщах отложений ледников, обусловливают формирование наиболее крупных селей. В высокогорьях, где часто преобладают весьма крутые скальные склоны, распространены скальные селевые очаги, неотъемлемой частью которых являются так называемые обвально-скальные ниши. Развитие и распространение селевых рытвин, упомянутых выше, наблюдается повсеместно, однако их морфологический вид и особенности весьма различны в зависимости от тех или иных горных зон. Наконец, эродированные поверхности приурочены к относительно пологим склонам средне- и низкогорий, а также встречаются в пределах межгорных депрессий.

Все рассмотренные выше морфологически обусловленные типы селевых очагов в пределах Республики Северная Осетия Алания в настоящее время испытывают весьма серьезную антропогенную нагрузку, что, безусловно, приводит во многом к интенсификации процессов селепроявлений.

Основную роль в горной части рассматриваемой Республики играют так называемые сели низкой плотности - наносоводные, которые формируются на территории всех морфоструктур Республики, но преобладают в зонах средне- и низкогорий или межгорных депрессий. Как известно, в пределах Северной и Южной юрских депрессий возможно образование в равной мере как наносоводных, так и грязекаменных селей. В высокогорной зоне в свою очередь ведущую роль играют грязекаменные сели. В частности, грязевые потоки были зафиксированы в районах Пастбищного и Лесистого хребтов.

Твердой составляющей селей в высокогорной зоне являются рыхлообломочные накопления скального пояса, флювиогляциальные, древние и современные моренные отложения ледников, иногда куски и глыбы льда, обрушивающиеся при пульсации 
ледников или обвалов некоторых висячих ледников (например, Майлинского и Колкинского в бассейне р. Геналдон); в зонах средне- и низкогорий наиболее распространен грубообломочный материал осыпей, коллювия и террасового речного аллювия, включая рыхлый и обломочный материал обвалов, оползней, оплывин и отвалов горных выработок.

Основной особенностью селевых потоков в горной части является то, что они формируются не на главных реках, a на их притоках и даже на притоках притоков, во время движения по которым они размывают днища русел, значительно увеличивая свою твердую составляющую. Так, начальный объем селевого потока по пути своего движения увеличивается в несколько раз по сравнению с изначальным объемом в очаге зарождения. При попадании в русло водотока более крупного порядка селевой поток трансформируется. Селевые паводки, как известно, формируются в русле главной реки в результате трансформации грязекаменных и наносоводных потоков, а также при размыве русловой самоотмостки, пойменных отложений и рыхлообломочных пород, слагающих ее берега. Поэтому населенные пункты и другие хозяйственные объекты, особенно Военно-Грузинская и Военно-Осетинская автомобильные дороги, страдают не столько от селевых потоков, сколько от обусловленных ими катастрофических селеподобных паводков (как, например, имевших место на реках Урух, Белая (приток р. Терек), Ардон, Фиагдон, Гизельдон, Геналдон, Терек в 1953, 1967, 2002 гг.).
В Республике Северная Осетия - Алания имеется 196 основных селевых русел, из них соответственно в бассейнах Хазнидона - 1, Уруха -58, Белой - 7, Ардона - 80, Фиагдона - 27, Гизельдона - 14, Терека 6, Камбилеевки - 3, по которым за период 1834-2014 гг. зафиксировано 643 схода селевых потоков (табл. 1).

По генезису выделяют четыре генетических типа селей, к которым относят следующие: дождевые, ледниковые, снеговые, а также сели, возникающие от прорыва запруд. Они имеют зональный характер распространения и существенные различия в селевом режиме. В среднем на дождевые сели приходится $94 \%$ случаев их схода, на ледниковые - 4 \%, на снеговые $-1,5 \%$ и от прорыва естественных запруд - 0,5\% (табл. 2).

На территории исследуемой Республики преобладают селевые потоки дождевого генезиса, распространяясь на всех высотных интервалах, во всех селевых бассейнах и очагах любого типа, формируясь после длительных затяжных дождей. Описываемые сели обеспечивают предварительное увлажнение рыхлообломочного материала, завершающегося ливнем, с выпадением не менее 30 мм атмосферных осадков за дождь интенсивностью 0,1-0,2 мм/мин. Примером этого могут служить сели, прошедшие 5 августа 1967 г., 18-19 июня 2000 г. и 20-22 июня 2002 г., когда отмечалось прохождение особо крупных селевых потоков, причем во всех основных речных бассейнах Республики $[2,3]$.

Таблица 1

Частота селевых потоков в долинах главных рек Республики Северная Осетия - Алания за 1834-2014 гг. (составлена автором по данным СК УГМС)

\begin{tabular}{|c|c|c|c|c|c|c|c|}
\hline Годы & Урух & Ардон & Фиагдон & Гизельдон & Геналдон & Терек (истоки) & $\begin{array}{c}\text { Число случаев } \\
\text { ВСЕГО }\end{array}$ \\
\hline $1834-2014$ & 98 & 397 & 70 & 32 & 25 & 21 & 643 \\
\hline
\end{tabular}

Таблица 2

Генетические типы селевых потоков на территории Республики Северная Осетия - Алания (1834-2014 гг.)

\begin{tabular}{|l|c|c|}
\hline \multirow{2}{*}{ Генетический тип селевого потока } & \multicolumn{2}{|c|}{ Случаи проявления } \\
\cline { 2 - 3 } & Число & \% \\
\hline Дождевой & 605 & 4 \\
\hline Ледниковый & 23 & 1,5 \\
\hline Снеговой & 11 & 0,5 \\
\hline Прорыв естественной запруды & 4 & \\
\hline
\end{tabular}


Таблица 3

Частота проявления катастрофических селей в наиболее опасных селевых бассейнах

\begin{tabular}{|l|l|l|}
\hline \multicolumn{1}{|c|}{ Бассейн реки } & \multicolumn{1}{|c|}{ Селевой бассейн } & \multicolumn{1}{c|}{$\begin{array}{c}\text { Годы катастрофических } \\
\text { проявлений селей }\end{array}$} \\
\hline \multirow{2}{*}{ Ардон } & Касайкомдонский & $1937,1953,1967,1975$ \\
\hline \multirow{5}{*}{} & Малый Лабагомский & $1937,1953,1967,1975$ \\
\cline { 2 - 3 } & Сказский & $1953,1967,1973$ \\
\cline { 2 - 3 } & Орахкомдонский & 1953,1973 \\
\cline { 2 - 3 } & Садонский & 1914,1958 \\
\cline { 2 - 3 } & Мизурский & $1907,1914,1958,1980$ \\
\hline Гизельдон & Геналдон & $1834,1902,2002$ \\
\hline Терек & Чмийский & 1953,1972 \\
\hline
\end{tabular}

Значительно реже в чистом виде возникают ледниковые и снеговые сели. Причинами формирования ледниковых селей являются как высокие температуры воздуха, которые обеспечивают активное таяние снега и льда на ледниках, достигая абсолютных максимумов значений до $30-32^{\circ} \mathrm{C}$ при средней температуре воздуха за одну-две предшествующие декады в $20-25^{\circ} \mathrm{C}$, так и прорывы ледниковых запруд, внутриледниковых вод, ледниковых и приледниковых озер; пульсация ледников и обвалы висячих ледников. Снеговые сели во многом обусловливаются интенсивным сходом снежного покрова достаточной мощности, a также способствующей селепроявлениям метеорологической ситуацией. Однако чаще всего отмечаются не только ледниковые или снеговые, но и смешанные сели, возникающие и развивающиеся после продолжительного периода с весьма высокими температурами воздуха, когда фронтальные или конвективные ливни провоцировали образование селевого потока.

Селеопасный период на территории Республики с учетом единичных селепроявлений длится с марта по октябрь, хотя иногда его продолжительность в условиях преобладания дождевых селей определяется изменением высоты нулевой изотермы и продолжительностью периода выпадения жидких осадков, варьируя от четырех месяцев в высокогорной зоне до семи-восьми месяцев в пределах средне- и низкогорий с нарушенным почво-растительным покровом. Стоит отметить, что в пределах Северной Осетии - Алании сели различной интенсивности, возникающие и развивающиеся в разнородных условиях, наблюдаются практически ежегодно. При этом повторяемость селепроявлений характеризуется от очень низкой (30-100 лет) до высокой (ежегодно, несколько раз в год из од- ного селевого района), составляя в среднем по территории 1 раз в 3-5 лет (табл. 3).

Наиболее часто сели формируются в бассейне р. Ардон. На их долю приходится около $62 \%$ всех зарегистрированных случаев селеформирований. В долинах притоков р. Ардон они случаются практически ежегодно.

Установлено, что сели небольших объемов (менее 10 тыс. м³) возникают и развиваются на всей территории ежегодно; сели средних (10-100 тыс. м ${ }^{3}$ ) и значительных (100-1000 тыс. м ${ }^{3}$ ) объемов в свою очередь - 1 раз в 3-5 и 5-8 лет соответственно. Катастрофические сели с очень значительными объемами (более $1000000 \mathrm{~m}^{3}$ ) формируются в среднем 1 раз в 25 лет. В наиболее селеактивных районах, в бассейне p. Ардон: Касайкомдонском, Малом Лабагомском, Сказском - в среднем возникают и развиваются 1 раз в 10-12 лет. По количеству катастрофических селей весьма известно Цейское ущелье бассейна р. Ардон, в котором за последние 50 лет зарегистрировано 6 селевых выносов объемами более $1000000 \mathrm{~m}^{3}$ [4].

Меру опасности селевых очагов определяют объемы единовременных выносов грязекаменных потоков и максимальные расходы наносоводных потоков наряду с некоторыми другими характеристиками.

Селевые потоки, формирующиеся в районах Бокового и Главного хребтов, котловинах Северной юрской сланцевой депрессии (Донифас-Фаснальской на р. Урух; Садоно-Унальской на р. Ардон; Верхне-Фиагдонской на р. Фиагдон, Даргавской на р. Гизельдон, Канидонской на р. Геналдон; Армхи-Джайраховской на р. Терек) и Южной Юрской сланцевой депрессии (Туальской на р. Ардон), отличаются весьма существенными объемами материала. Здесь преобладают сели сред- 
ней активности с объемами 100-100 000 м³, а в отдельных случаях образуются сели высокой степени опасности, с объемами от $1000000 \mathrm{~m}^{3}$ (р. Ардон) до 65-70 млн $\mathrm{M}^{3}$ (р. Геналдон). В районе Скалистого хребта образуются сели низкой активности со средними объемами 100-10 $000 \mathrm{~m}^{3}$, но в общем в районе Скалистого, Пастбищного, Лесистого, Кабардино-Сунженского, Терского хребтов, Аргуданской предгорной холмистой возвышенности преобладают селевые потоки очень низкой активности с небольшими, менее 10 тыс. м ${ }^{3}$, объемами. Толщина выносов отдельных селевых потоков может достигать 5-6 м, а в среднем составляет 0,4-3,0 м [5].

Селевые процессы обусловливают для всех отраслей экономики горных районов Северной Осетии - Алании значительный ущерб, иногда их прохождение сопровождается человеческими жертвами. Хорошо известны катастрофические селевые потоки, прошедшие в августе 1953 г. в долине р. Цеядон. Тогда со склонов Цейского ущелья сошло 10 селевых потоков. Наиболее разрушительным из них был «Медик», сформировавшийся по ручью, впадающему в р. Цеядон в 0,5 км выше устья р. Сказдон. При выходе этого ручья из узкой теснины в долину р. Цеядон располагался альпинистский лагерь «Медик». Сель начался в 2 часа ночи. Проснувшиеся от страшного грохота альпинисты выбежали из палаток и помещений. На них двигалась огромная серая масса из валунов и камней. Она накрыла все палатки и ворвалась в окна и двери домов. Отдельные валуны достигали 3,5-4,0 м в диаметре. Два одноэтажных финских домика были перемещены на расстояние 30-50 м. Селевой поток двигался с перерывами до 5 часов утра. Проливной дождь не прекращался ни на минуту. Высокие валы щебня и валунов образовали широкую просеку в лесу. Длина селевого выноса достигала 500 м при ширине около 50 м и средней мощности 3,5-4 м [6].

В середине июля 1958 г. селями были поражены склоны Скалистого хребта в бассейне р. Ардон. Особенно разрушительный сель прошел в долине р. Садон - левого притока р. Ардон. Он сформировался в русле небольшого ручья Ходка, впадающего в р. Садон. Со слов местных жителей, очевидцев селя, 12 июля в 5 часов утра вода в р. Ходка начала быстро прибывать. Раздался страшный грохот, и ручей моментально изменился до неузнаваемости. Вода в нем как бы вскипела, стала черной и гу- стой от грязи, ила и камней. Она с шумом и грохотом врывалась в близлежащие поселения, при этом конус выноса Ходкинского селя практически полностью покрыл поселок Садон, достигая в длину около 200 м, в ширину - 100-200 м, а его толщина составила 4,5-4,0 м [7]. Как показано в ряде научных работ $[7,8]$, этим селем было вынесено около 120 тыс. м³ твердого материала.

Довольно крупный сель прошел в это время и по руслу ручья Ногкау - левому притоку р. Ардон, впадающему в нее у г. Мизур. Вынесенный этим селем твердый материал разрушил всю северную часть г. Мизур, размыл на значительном протяжении дорогу Алагир - Мизур [8].

Таким образом, в представленном выше исследовании показано, что около $60 \%$ территории Республики Северная Осетия Алания подвергаются или могут быть подвергнуты прохождению селевых потоков разной степени опасности. При этом наносится огромный ущерб 103 объектам экономики, в том числе: 70 населенным пунктам, 5 хозяйственным объектам, 5 оздоровительным учреждениям, 23 участкам автомобильных дорог.

\section{Заключение}

Периодичность схода селевых потоков на территории горной части Республики Северная Осетия - Алания составляет в среднем 1 раз в 3-5 лет, а катастрофических 1 раз в 25 лет. В отдельные годы отмечается массовый сход селевых потоков, всегда связанный с выпадением большого количества атмосферных осадков редкой повторяемости. Необходимо отметить, что в дальнейшем, по мере возрастания рекреационного и хозяйственного освоения горных районов Республики Северная Осетия - Алания, особенно в связи с развитием горнорудной промышленности, строительством автомобильных дорог, интенсивными лесоразработками и выпасом скота, будет возрастать и активность селевых явлений, а следовательно, и селевая опасность. Этому также способствует и нестабильность погодно-климатического режима изучаемой территории.

\section{Список литературы / References}

1. Сергеева Г.А., Волобуева Л.Л., Кривошеева Е.А. Долгосрочный прогноз развития и направления изучения селевых явлений на горной территории Карачаево-Черкесии. Меры защиты от селей // Инженерный вестник Дона. 2012. № 4-1 (22). [Электронный ресурс]. URL: http://www. ivdon.ru/ru/magazine/archive/n4p1y2012/1155 (дата обращения: 21.01.2020).

Sergeeva G.A., Volobueva L.L., Krivosheeva E.A. Longterm forecast of development and direction of study of mud phe- 
nomena in the mountainous territory of Karachay-Cherkessia. Measures of protection against mudslides / Inzhenernyj vestnik Dona. 2012. № 4-1 (22). [Electronic resource]. URL: http:// www.ivdon.ru/ru/magazine/archive/n4ply2012/1155 (date of access: 21.01.2020) (in Russian).

2. Андреев С.С., Попова Е.С. Колебания среднегодовой температуры воздуха по данным г. Махачкала/Уйташ в 1882-2015 гг.// Успехи современного естествознания. 2017. № 5. C. 72-77.

Andreev S.S., Popova E.S. Fluctuations in the average annual air temperature according to the data of Makhachkala/ Uytash in 1882-2015 // Advances in current natural sciences. 2017. № 5. P. $72-77$ (in Russian)

3. Андреев C.C., Андреева Е.С. Биоклиматическая характеристика Ростовской области по индексу патогенности метеорологической ситуации // Известия высших учебных заведений. Северо-Кавказский регион. Естественные науки. 2003. № 9. C. 67-69.

Andreev S.S., Andreeva E.S. Bioclimatic characteristics of the Rostov region according to the pathogenicity index of the meteorological situation// Izvestiya vysshih uchebnyh zavedenij. Severo-Kavkazskij region. Estestvennye nauki. 2003. № 9. Р. 67-69. (in Russian).

4. Бойнагрян В.Р., Бойнагрян А.В., Манукян Н.В. Селевая активность в Армении // Сборник трудов III Международной конференции «Селевые потоки: катастрофы, риск, прогно3, защита». 22-26 сентября 2014. Южно-Сахалинск: Изд. Сахалинский филиал ФГБУН Дальневосточный геологический институт ДВО РАН, 2014. С. 10-13.

Bojnagryan V.R., Bojnagryan A.V., Manukyan N.V. Mudflow activity in Armenia // Sbornik trudov III Mezhdunarodnoy konferentsii «Selevyye potoki: katastrofy, risk, prognoz, zashchita». 22-26 sentyabrya 2014. Yuzhno-Sakhalinsk: Izd.Sakha- linskiy filial FGBUN Dal'nevostochnyy geologicheskiy institut DVO RAN, 2014. P. 10-13 (in Russian).

5. Кононова Н.К. Связь стихийных бедствий в России в 2013 и 2014 гг. с циркуляцией атмосферы северного полушария // Сложные системы. 2014. № 4 (13). С. 46-60.

Kononova N.K. Connection of natural disasters in Russia in 2013 and 2014 with the circulation of the atmosphere of the Northern hemisphere // Slozhnye sistemy. 2014. № 4 (13). P. 46-60 (in Russian).

6. Бероев Б.М., Казахова М.Г. О состоянии и перспективах развития туристско-экскурсионного дела в Северной Осетии-Алания // Географический вестник. 2012. № 2 (21). C. 93-101.

Beroev B.M., Kazahova M.G. About the state and prospects of development of tourist and excursion business in North Ossetia-Alania// Geograficheskij vestnik. 2012. № 2 (21). P. 93-101 (in Russian).

7. Геккиев А.Б. Влияние рельефа на климат республики Северная Осетия-Алания // Современные наукоемкие технологии. 2012. № 1. С. 5-7.

Gekkiev A.B. Influence of terrain on the climate of the Republic of North Ossetia-Alania // Modern high technologies. 2012. № 1. P. 5-7 (in Russian).

8. Гуцаева А.Б. Потенциал Республики Северная Oceтия - Алания для формирования конкурентоспособного туристско-рекреационного комплекса в рамках СевероКавказского федерального округа // Молодой ученый. 2013. № 6. С. 797-799.

Gucaeva A.B. Potential of the Republic of North OssetiaAlania for forming a competitive tourist and recreational complex within the North Caucasus Federal district// Molodoj uchenyj. 2013. № 6. P. 797-799 (in Russian). 